\title{
EduCAÇÃo INTEGRAL NA CIDAdE: PROCESSOS DE FORMAÇÃO DE TERRITÓRIOS EDUCATIVOS NA EXPERIÊNCIA DE Belo Horizonte, Minas Gerais, Brasil
}

Integrated education in the city: processes of forming educational territories in the Belo Horizonte experience, Brazil

\author{
Paulo Felipe Lopes de Carvalho \\ Universidade Federal de Minas Gerais, Brasil \\ Lúcia Helena Alvarez Leite \\ Universidade Federal de Minas Gerais, Brasil
}

\begin{abstract}
RESUMO: O artigo discute a relação entre a escola, o bairro e a cidade no âmbito do Programa Escola Integrada/PEI, a experiência Educação Integral de Belo Horizonte/MG/Brasil. A partir de uma investigação qualitativa etnográfica, que envolveu um grupo de adolescentes e educadores participantes do Programa, foi possível compreender que a constituição de territórios educativos está fortemente relacionada com a ligação dos estudantes ao bairro, bem como com as relações de poder que são inerentes à cidade. Esses elementos, que formam as bases do território educativo, têm possibilitado a emergência de ações coletivas, através da escola, que conduziram à melhoria de espaços na comunidade, e proporcionado um processo educativo mais próximo da vivência quotidiana dos estudantes.
\end{abstract}

Palavras-Chave: educação integral, cidade, território, território educativo.

RESUM: En aquest treball s'analitza la relació entre l'escola, el barri i la ciutat en el marc del Programa Escola Integrada (PEI), l'experiència d'Educació Integral de Belo Horizonte, Minas Gerais, Brasil. A partir d'una recerca etnogràfica que va involucrar un grup d'adolescents i educadors participants del programa, va ser possible comprendre que l'establiment de territoris educatius es relaciona fortament amb la connexió dels estudiants amb el barri, així com 
amb les relacions de poder inherents a la ciutat. Aquests elements, que constitueixen el fonament del territori educatiu, han permès el desenvolupament d'accions col·lectives a través de l'escola, amb la millora dels espais en la comunitat $i$ han proporcionat un procés educatiu més pròxim a la vida quotidiana dels estudiants.

Paraules clau: educació integral, ciutat, territori, territori educatiu.

RESUMEN: Este artículo analiza la relación entre la escuela, el barrio y la ciudad en el marco del Programa Escola Integrada (PEI), la experiencia de Educación Integral de Belo Horizonte, Minas Gerais, Brasil. A partir de una investigación etnográfica que involucró a un grupo de adolescentes y educadores participantes en el programa, fue posible comprender que el establecimiento de territorios educativos se relaciona fuertemente con el vínculo de los estudiantes con el barrio, así como con las relaciones de poder que son inherentes a la ciudad. Estos elementos, que constituyen el fundamento del territorio educativo, han permitido el desarrollo de acciones colectivas a través de la escuela, con la mejora de los espacios en la comunidad, y han proporcionado un proceso educativo más cercano a la vida cotidiana de los estudiantes.

Palabras clave: educación integral, ciudad, territorio, territorio educativo.

ABSTRACT: This paper discusses the relationship between school, the neighborhood and the city within the Programa Escola Integrada (PEI) (Integrated School Program), the full-time education experience of Belo Horizonte, Minas Gerais, Brazil. An ethnographic research experience involving a group of adolescents and educators taking part in the program revealed that establishing educational territories is closely related to the students' connection with the neighborhood, as well as with the city's inherent power relations. These elements, which form the basis of the educational territory, have enabled collective actions to be developed through the school, with the improvement of spaces in the community, and have provided an educational process that comes closer to students' daily lives.

KEYWORDS: integrated education, city, territory, educational territory. 


\section{Introdução}

$\mathrm{E}$

ste artigo tem origem numa investigação de mestrado, concluída em 2014, que teve como objeto de estudo o Programa Escola Integrada/PEI da Secretaria Municipal de Educação de Belo Horizonte/smed - BH, bem como os processos de formação de territórios educativos viabilizados pelo Programa que, assim como muitas experiências, políticas, programas e projetos contemporâneos em Educação Integral no Brasil, articulam os processos educativos vivenciados na escola com os vivenciados nos territórios do bairro e da cidade.

No Brasil, a Educação Integral é diversa do ponto de vista paradigmático e prático. Nesse sentido, expomos aqui a conceção de Educação Integral que utilizamos para fins deste texto e como podemos entender esse fenómeno na atualidade a partir da experiência de estudantes de escolas públicas que vivem em territórios do país caracterizados por pobreza social. ${ }^{1}$

Aponta-se assim para uma Educação Integral que seja capaz de desenvolver uma formação de crianças e jovens que seja perpendicular aos campos da cultura, à relação com a comunidade e com a família e também ao diálogo com os territórios da cidade. A questão da ampliação do tempo interage com a vivência desse tempo alargado. Nessa perspetiva, a cidade é entendida como um grande território educador que contém diversos espaços educativos capazes de promover uma aprendizagem mais ampla, além de agregar novas formas e espaços que viabilizam o conhecimento.

A aprendizagem acontece ao longo de toda a vida em diferentes contextos: na família, na escola, na cidade; em espaços formais e informais [...]. No entanto, é preciso entender, também, que tempo e espaços escolares devem ser preenchidos com novas oportunidades para a aprendizagem e a reapropriação de espaços de sociabilidade e comunicação com a comunidade local, regional e global. (Brasil, 2008, p.35)

1. No Brasil, a ampliação da jornada escolar e a procura de uma formação mais completa é algo culturalmente existente nas classes economicamente privilegiadas. Facto que se traduz na disponibilização do tempo integral em diversas instituições de ensino privadas. Quando aqui centralizamos o desenvolvimento da Educação Integral contemporânea, focamos o público que vive em situação de pobreza social e que participa nas experiências no âmbito da educação pública. 
A escola, nesse cenário, não se consolida como a única instituição para a construção dos projetos de vida dos sujeitos, mas liga-se a outros espaços formativos. Mas ao focalizar a escola, urge que a entendamos como «lugar privilegiado de espaços e tempos educativos, formadores e culturais que se fazem importantes na vida dos sujeitos» (Arroyo, 2000).

Uma Educação Integral que efetivamente vise a ampliação da formação dos estudantes deve estar ligada ao território e à comunidade local. O território, neste contexto, assume um caráter popular e inscreve-se na aceção abordada por Santos (2000). De acordo com o autor, o território estabelece-se a partir da utilização que lhe foi atribuída e das relações sociais que o compõem, atribuindo um caráter dinâmico à categoria. Com essa prerrogativa do que é território, emerge um sentido não estático que se relaciona com o espaço vivido, onde se produzem relações.

Nesse sentido, a aceção de território e territorialidade pode exercer bastante importância nas práticas de jornada ampliada que exploram espaços para além dos muros da escola e, por consequência, podem suscitar a formação de territórios educativos. Posto isto, muitas experiências atuais revelam que a utilização de espaços exteriores à escola agregam aspetos formativos aliados a valores importantes, o que se reflete no sentimento de pertença social, podendo assim, reforçar laços comunitários. Nesse sentido, que agentes institucionais, formais, não formais, materiais e simbólicos têm uma atuação efetiva na tentativa de desenvolvimento e construção de um território educativo? Quem são os sujeitos atuantes na construção do território educativo? Quais as possíveis configurações deste território?

\section{O contexto explorado: o Programa Escola Integrada de Belo Horizonte}

O Programa Escola Integrada/PEI insere-se no movimento de multiplicação das experiências atuais de Educação Integral que visam uma perspetiva de formação dos territórios educativos e cidades educadoras. Desenvolvido pela Secretaria Municipal de Educação de Belo Horizonte, o PEI está em curso desde 2006. O objetivo central do Programa é desenvolver uma Educação 
Integral e Integrada a partir da extensão da jornada escolar em cinco horas diárias, além das quatro horas tradicionalmente atribuídas na organização do tempo escolar no Brasil, totalizando uma jornada de nove horas por dia.

O Programa é desenvolvido a partir de oficinas, que são desenvolvidas no turno oposto ao dedicado às disciplinas regulares, ou seja, no turno ampliado. As oficinas são vocacionadas para quatro áreas: Conhecimentos Específicos; Acompanhamento Pedagógico/trabalhos de casa; Formação pessoal e social; Cultura, Artes, Lazer e Desporto.

Diversos espaços sociais e instituições como ONG, associações comunitárias, centros de cultura, parques, clubes, igrejas, universidades, entre outros, são parceiros do PEI. Essas instituições contribuem de maneiras diversas para o desenvolvimento do programa, principalmente através da cedência de espaços para a realização das oficinas.

Nesse sentido, ressalta-se que o programa prioriza o desenvolvimento de atividades nos espaços do bairro e da cidade, no intuito de aliar e integrar a escola com o espaço social e cultural em que os alunos vivem. Adicionalmente, pretende-se estreitar a relação entre a escola e a comunidade para que os espaços nas redondezas da escola possam ser utilizados para as práticas realizadas no âmbito do PEI.

Com essas características inovadoras, no contexto de uma escola pública brasileira, emerge a necessidade de a escola pensar e repensar novas abordagens e organizações educacionais. Reforça-se nesse sentido a ideia de que:

Ao ampliar o olhar sobre as possibilidades de educação para além da escola, a escola não diminui nem restringe a importância e papel dela; apenas aponta que as demandas de educação e proteção poderiam ser mais bem atendidas com a articulação entre o saber escolar e os saberes que se descobrem por meio de outras formas de educação. (Guará, 2009, p.66)

\subsection{Programa Escola Integrada no Alto Vera Cruz}

O bairro Alto Vera Cruz está localizado na periferia de Belo Horizonte. Trata-se de um bairro marcado por consonâncias e dissonâncias sociais e culturais; se por um lado, episódios trágicos e a falta de infraestrutura do bairro 
marcam uma diferença social em relação a outros bairros, acentuando a sua situação de pobreza na metrópole Belo Horizonte, principalmente devido à intensidade da violência urbana; por outro, as ações coletivas, desenvolvidas pelas diversas mobilizações de caráter popular ao longo de toda a história do Alto Vera Cruz, fazem emergir o sentido de comunidade e solidariedade entre os moradores. Isto traduz-se na expressão de manifestações culturais várias, bem como no estabelecimento de instituições e organizações no território que têm atuação preponderante no desenvolvimento social do bairro. Verificamos na dinâmica do Alto Vera Cruz um forte movimento de bairro, do qual a escola também participa, inserindo-se numa luta local por reconhecimento das relações aí verificadas. Nesse sentido:

No Movimento de Bairro o espaço constitui um referencial direto e decisivo ao definir territorialmente sua base social, catalisa e referência simbólica e politicamente o enfrentamento de uma problemática com imediata expressão espacial, como a insuficiência dos equipamentos de consumo coletivo, problemas habitacionais, segregação sócio-espacial, intervenções urbanísticas autoritárias e deterioração da qualidade de vida na cidade. (Souza e Pedon, 2007. p. 140)

Nesse contexto, o Programa Escola Integrada foi implementado na Escola Municipal Admirável ${ }^{2}$ em 2008 e a partir dessa data os estudantes do programa começaram a seguir a rotina que a seguir especificamos. Os que frequentam o PEI durante a manhã, chegam à escola às $8 \mathrm{~h} 30$ e tomam o pequeno-almoço. De seguida frequentam as oficinas, regressando às 11h30; almoçam, têm um intervalo e às $13 \mathrm{~h} 00$ dirigem-se para as salas onde terão as aulas normais. Aqueles que tiverem aulas de manhã, chegam à escola às $7 \mathrm{~h} 00$, às $11 \mathrm{~h} 30$ almoçam e ficam no recinto até às $12 \mathrm{~h} 45$, hora em que vão para as oficinas. Às $16 \mathrm{~h} 00$, os estudantes voltam para a escola, fazem o último lanche do dia $\mathrm{e}$ às $16 \mathrm{~h} 30$ saem da escola.

A escola tem disponíveis oficinas de artesanato, skate, edição de um jornal, culinária, dança, teatro e circo, informática, acompanhamento pedagógico, pré-CEFET, desporto, polo aquático, pintura mural e horticultura. E os espaços utilizados para o desenvolvimento das oficinas são: CEVAE (Centro

2. Nome fictício atribuído à escola para fins da investigação. 
de Vivência Agroecológica), praça Padre Marcelo, Associação Comunitária Alto Vera Cruz, clube Santa Cruz e esporadicamente o Centro Cultural Alto Vera Cruz.

A escola em causa sempre teve a preocupação de estreitar os laços com a comunidade do bairro, tanto através da participação de membros da comunidade nos processos educativos como através da implementação de diversos programas e projetos dedicados a promover a relação escola-comunidade, entre outros. Assim, devido a essa característica histórica de aproximação ao bairro, a PEIEMA tem conseguido desenvolver o PEI de acordo com as suas conceções, que como já referimos, privilegia como objetivos a relação íntima entre a escola, o bairro, a cidade e os respetivos sujeitos.

Assim, do ponto de vista da Educação Integral para as classes populares de que aqui estamos a falar, o Programa Escola Integrada vai ao encontro da aceção de Arroyo (2012), a qual é por ele radicalizada no âmbito do debate da educação de tempo integral, afirmando que se oferecermos mais escola seguindo a mesma lógica do que acontece historicamente pela visão tradicional do direito à escolaridade, estaremos a perder o significado político desses programas que visam a promoção da educação integral para as classes populares.

Se um turno já é tão pesado para tantos milhões de crianças e adolescentes condenados a opressivas reprovações, repetências, evasões, voltas e para tão extensos deveres de casa, mais uma dose do mesmo será insuportável. (Arroyo, 2012, p. 33)

\section{Metodologia}

Para explorar mais aprofundadamente a relação da escola com o bairro e com a cidade, desenvolvemos uma investigação qualitativa numa perspetiva etnográfica, que pode ser entendida como «o tipo de esforço intelectual que ela representa: um risco elaborado para uma descrição densa» (Geertz, 1989, p. 17). Essa posição foi assumida em todo o percurso realizado ao longo do processo empírico da investigação. 
Desenvolvemos, portanto, uma investigação qualitativa, estabelecendo um diálogo entre a cidade e a etnografia. Essa preocupação, nesta investigação, coloca-se a partir do movimento de desenvolvimento da Educação Integral, como já mencionado e discutido anteriormente. Isso porque, nesse movimento, as cidades e o fenómeno urbano assumem um papel central, considerando que Belo Horizonte é uma Cidade Educadora.

Para tanto, trabalhamos com a conceção de Magnani (2002) atribuindo à investigação um olhar de perto e de dentro. que permite dar mais visibilidade aos sujeitos que ocupam as cidades, no nosso caso educadores e estudantes em circulação promovida pelo PEI. Nesse sentido, o autor coloca questões que sugerem outro olhar sobre as cidades, para além do quadro caótico, geralmente exposto pelos autores que discutem o tema. Um olhar que privilegie os sujeitos da e na cidade, as suas práticas sociais e culturais no contacto com a cidade.

Tomando como base essa discussão, empreendemos um processo empírico, no qual evitámos a dicotomia existente entre as estruturas urbanas e os indivíduos. De acordo com o exposto, entrámos num território singular em Belo Horizonte, o Alto Vera Cruz, bem como uma escola pertencente ao bairro, a Escola Municipal Admirável, ${ }^{3}$ onde durante aproximadamente seis meses, entre 2013 e 2014, desenvolvemos a investigação, junto aos sujeitos.

O trabalho compreendeu o acompanhamento contínuo de um grupo de adolescentes participantes do PEI nos seus percursos diários, tanto no turno regular como no turno de tempo ampliado (contraturno). É importante destacar que no processo de construção dos dados, foram realizadas com os adolescentes oficinas de mapas mentais. Segundo Kozel (2009), esses mapas são instrumentos que revelam a relação do indivíduo com um determinado espaço. Nesse sentido, a representação dos mapas, no nosso caso, ilustra e oferece elementos para analisarmos a experiência espacial vivenciada pelos sujeitos no PEI. No percurso metodológico da investigação, foram realizadas também entrevistas individuais e em grupo com os educadores do Programa, a professora comunitária e o grupo de formadores das oficinas.

3. Nome fictício utilizado para fins de pesquisa. 


\section{A escola vai ao encontro do bairro e da cidade: $O$ território educativo nas ligações territoriais}

Os processos de constituição dos territórios educativos são complexos e marcados por processos de territorialização diversos, no bairro e na cidade. Entre eles, destacou-se a ligação estabelecida pelos sujeitos do Alto Vera Cruz ao território, bem como as relações dos educadores do território ao humanizar a e interrogar a docência, bem como as relações de poder inerentes à formação do território educativo. Elementos que iremos discutir a seguir.

A partir de considerações de Haesbaert (2007) sobre a categoria território e da dinâmica desenvolvida pelas relações educativas engendradas pelo PEI, conseguimos perceber um território educativo composto de multiterritorialidades e que afirma a identidade da comunidade e do território do ambiente escolar. Isso, na medida em que existe um estreita ligação entre as relações educacionais produzidas pela escola e a presença dos estudantes nos espaços do bairro; elementos esses que valorizam e intensificam, mesmo face às relações de poder, a identidade territorial e o sentido de bairro (vizinhança). Assim, o território educativo, ao assumir contornos fluidos e múltiplos, incorpora um caráter multiterritorial.

Além da multiterritorialidade e da fluidez do território educativo, potencializa-se também o sentimento pelo bairro, uma vez que a definição de bairro está intimamente ligada à afirmação das identidades e à coesão social. Nesse sentido, quando a escola focaliza os movimentos do bairro e se relaciona com eles, ao apropriá-los, a escola insere-se também numa luta pelo reconhecimento das relações ali verificadas.

Nesse sentido, o que nos despertou bastante atenção foi perceber como o sentimento de pertença ao Alto Vera Cruz foi e é determinante no delineamento do território educativo. Emergem na dinâmica do Programa situações de sociabilidade que se assemelham às relações familiares, por exemplo. Relações essas percebidas principalmente pela proximidade entre os sujeitos ao comunicarem entre si de distintos e diversos modos, ou seja, nas conversas entre os estudantes, na relação dos estudantes com os formadores das oficinas, entre os diálogos dos formadores das oficinas, nos encontros dos 
estudantes com os moradores da comunidade quando circulavam no bairro. Além disso, relatos de diversos sujeitos durante a investigação empírica afirmavam o quanto se sentiam ligados àquele território. É importante referir que a ligação de que estamos a falar não se estabelece apenas pelo facto de o sujeito ter nascido ou viver no referido território. Mas, principalmente, por reconhecê-lo enquanto espaço de reprodução da vida e a partir daí focalizar mudanças e novos modos de apropriação.

Nesse sentido, cabe realçar os seguintes diálogos:

Investigador: Achas que o teu sentimento pelo bairro tem a ver com a presença da escola aqui no Bairro?

Henrique: Os dois tão juntos. Porque os meus pais já estudaram aqui, onde eu nasci, os meus pais já estudaram aqui. É importante essa escola aqui, porque há muitas escolas aqui em volta. Eu gostei desta escola para estudar. É perto de casa também. E eu gosto desta escola. Ainda mais que este é o meu último ano. Nem sei bem como vai ser quando sair desta escola.

Xisto: É diferente! Porque lá (os diversos espaços das aulas - passeios) é uma coisa e aqui (O Alto Vera Cruz) é outra.

Investigador: Mas o que achas diferente?

Xisto: As pessoas, o jeito delas. Aqui são de um jeito e lá são de outro.

Investigador: Como assim?

Xisto: Lá elas são mais tolas. Tipo assim...

Professora Comunitária: Este é um bairro muito unido, quando há algum problema, juntamo-nos para resolver as questões. Por exemplo, a questão do lixo perto do posto de saúde, a comunidade inteira envolveu-se, a semana inteira a trabalhar, foi assim que conseguimos.

Ao analisarmos o discurso de Henrique, é nítida a perceção da relação estreita entre o bairro e a escola. Ao ser indagado sobre o porquê do sentimento de intimidade e afeto pelo bairro, o estudante relaciona estes sentimentos imediatamente com a presença da escola naquele território. Ao dizer que os seus pais estudaram ali, o estudante evidencia um sentimento de pertença ao território, ao relacionar as suas raízes familiares com a experiência escolar por ele vivenciada. 
Em referência ao discurso de Xisto, há uma comparação com as vivências no bairro e com as suas perceções sobre o Alto Vera Cruz. Ao discorrer sobre as pessoas que vivem nesses diferentes territórios, o estudante diferencia claramente os seus modos de ser. Nessa comparação, as pessoas de lá, ou seja, que não pertencem ao território do Alto Vera Cruz são consideradas pelo educando como mais tolas, o que marca uma diferença cultural entre as experiências extraterritoriais e aquelas vivenciadas no território do bairro, as quais geram o sentimento de intimidade.

Já o discurso da professora comunitária expõe como o Alto Vera Cruz é marcado pelo envolvimento da comunidade em ações coletivas que visam a melhoria do bairro. Aqui, vale a pena ressaltar a ação da escola, pois a escola assume-se como instituição promotora de algumas ações, o que se dá pelo facto de a escola ser uma referência institucional na comunidade ao reconhecer as características territoriais do bairro. Além, disso, a ligação que a professora comunitária estabelece com o Alto Vera Cruz potencializa essas ações, uma vez que procura, a partir da ligação territorial, a modificação do espaço, modificações essas que podem levar os sujeitos a criarem novas relações com um determinado espaço. A esse nível, quando a escola se liga ao bairro, podem ser desenvolvidas ações coletivas com vista a modificar o espaço e a torná-lo mais propício para as atividades escolares e também para a reprodução da vida no quotidiano do território onde a escola se localiza. Emerge, assim, uma relação dialógica entre a escola e o seu ambiente.

Com isso, tal como já assinalámos, a transformação do espaço, nessa ação como entre outras, legitima a ideia de que a escola em contacto com seu território pode promover modificações e melhorias físicas no bairro. Além disso, pode também potencializar os laços de intimidade dos estudantes e dos moradores do território com o espaço do bairro e com o espaço da escola. Relações que se desdobram na efetivação de sentimentos de pertença, ou seja, de pertença ao espaço.

Nesse sentido, segundo considerações de José de Deus (2010), os sentimentos de pertença, chamados topofílicos associam-se aos lugares valorizados pelos sujeitos. No contexto da investigação, visualizam-se as ações de melhoria dos espaços do bairro desenvolvidas pela escola no contexto do Pro- 
grama Escola Integrada. Ações que pretendem modificar espaços degradados do bairro, a fim de que estes possam ser mais propícios para apropriação tanto dos estudantes, quanto da comunidade. Essas melhorias físicas e simbólicas no espaço podem ser entendidas como ações de toporreabilitação, que são ações de resgate, reabilitação ou restauração de lugares, paisagens e conjuntos (Amorim Filho, 1999).

Assim, podemos perceber como a imagem do bairro para alguns adolescentes tem uma relação de vínculo, intimidade e efetivação do espaço enquanto palco de experiências e relações sociais. Além disso, pressupõe a afirmação da identidade do bairro e das vivências territoriais que ali se processam. Nesse sentido, afirma-se uma identidade no âmbito do território, fazendo-se por desenvolver territorialidades imprimidas no espírito de coletividade presente nas relações do bairro. Neste contexto, a territorialidade ao mesmo tempo que procura a efetivação da identidade, ordena o território e organiza-o de forma particular de acordo com o grupo que o territorializa, delineando assim um processo de formação das identidades territoriais. Processo esse, potencializado com a presença do PEI no bairro, o que consequentemente estreitou os laços da relação escola-território.

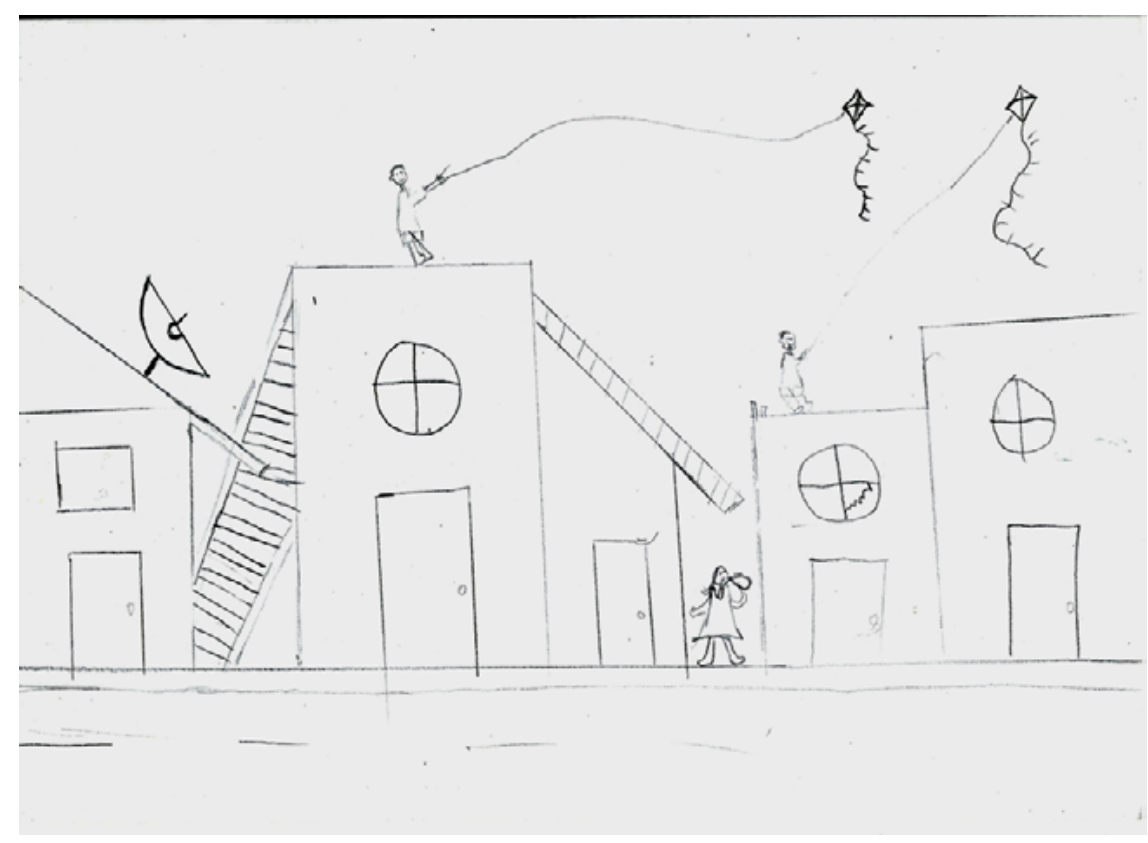

Figura 1. Mapa metal/Brincadeiras no meu lugar.

Autor: estudante/PEI. 
$\mathrm{Na}$ imagem representada por um estudante, podemos perceber a experiência do território imprimida nas brincadeiras que ali se desenrolam quotidianamente. Nesse sentido, corrobora-se a ideia de que um dos processos de formação de territórios educativos está associado ao sentimento de pertença dos sujeitos ao espaço do bairro, o que está relacionado com a conceção de Carlos (1996), para quem o lugar se configura como «uma porção do espaço apropriável para a vida - apropriada através do corpo - dos sentidos - dos passos de seus moradores» (p. 201). Desta forma, de acordo com considerações de Kozel (2010), os seres humanos atribuem significados e organizam o espaço de acordo com os símbolos que constroem a partir da sua perceção.

Emerge, a partir da ação territorializada da escola, o sentido de lugar que se liga intrinsecamente ao território, pois em ambos está presente a afirmação das identidades enquanto parte da sua formação. A escola, então, em consequência das suas ações no âmbito da jornada ampliada no bairro, incita a constituição do lugar que «é a base da reprodução da vida e pode ser analisado pela tríade habitante-identidade-lugar» (Carlos, 1996, p. 20). Assim, «o espaço transforma-se em lugar à medida que adquire definição e significado» (Deus, 2010, p. 20).

Indo ao encontro dessa perspetiva sobre a dimensão do lugar que emerge das relações visualizadas no quotidiano do território investigado, podemos perceber como a imagem do bairro para alguns adolescentes tem essa relação de ligação, intimidade e efetivação do espaço enquanto palco de experiências e relações sociais. Adicionalmente, pressupõe a afirmação da identidade do bairro. Nesse sentido, afirma-se uma identidade no âmbito do território, que faz por desenvolver uma territorialidade imprimida no espírito de coletividade nas relações do bairro. A esse nível, a territorialidade ao mesmo tempo que procura a efetivação da identidade, organiza o território e fá-lo de forma particular - no nosso caso através da ação escolar - de acordo com o grupo que o territorializa, delineando assim um processo de formação das identidades territoriais. 


\section{Os conflitos pelo espaço e as relações de poder na educação na cidade}

Inerente aos processos de construção de territórios educativos e ao encontro da escola com a cidade, as disputas pelo espaço fazem emergir relações de poder na dinâmica territorial do Programa Escola Integrada. Relações marcadas por características sociais do território do Alto Vera Cruz como, por exemplo, o tráfico de droga presente nalguns pontos do espaço e os episódios de violência que decorrem dessa atividade. É necessário visualizar essas dimensões de poder intrínsecas à constituição de territórios educativos, pois estas disputas muitas vezes impedem que a escola extrapole os seus muros e expanda o seu espaço educativo, pelo medo da violência urbana que, muitas vezes, decorre dos conflitos por espaço, comuns em qualquer território, mas intensificados nos territórios de periferia existentes nas metrópoles brasileiras.

Elizabeth: Eu gosto de algumas ruas, de alguns lugares. Mas de alguns lugares não gosto. Passamos na rua e as pessoas começam a discutir do nada. Lá debaixo do Rocha, vemos muita gente a lidar com essas coisas

Investigador: Drogas?

Elizabeth: Sim.

Investigador: E Rocha é o quê?

É uma rua. A rua chama-se Rua do Rocha. Temos que passar perto da rua para ir para o Sacolão, perto da rua para ir para o BH.

Pedro: Gosto do bairro, exceto das confusões que ocorrem. Tiros, essas coisas assim. Nó Cruzeirinho, Rocha tudo... Dá mais os povo noiado. Tenho amigos que moram lá, mas não fazem nada.

(Arquivos de campo)

Xisto: Tenho muitos amigos envolvidos com droga. Eu tenho vários amigos com quem o meu pai até me proibiu de andar porque fumam marijuana. Fazem essas coisas assim.

Investigador: E se tu não estivesses na Escola Integrada, seria mais fácil envolveres-te com isso? 
Xisto: Sim, aí não tinha nenhum lugar para ir. Ia pensar, ir para onde? Ia para onde eles me chamassem.

\section{(Arquivos de campo)}

Os diálogos apresentados evidenciam que, por parte dos estudantes, o sentimento de pertença ao bairro, está aliado ao reconhecimento das disputas e relações de poder presentes no território. Aliado a isso, algo que ficou evidente nas observações de campo foi que, no contexto escolar, as crianças levavam os seus relatos sobre os acontecimentos no bairro para a escola e junto com os formadores das oficinas projetavam possíveis soluções para os problemas observados, mesmo que esta solução, muitas vezes, não fosse implementada nos espaços que para eles representariam violência. Aliado a isso, quando circulavam pelo bairro, no âmbito do PEI, os estudantes, ao perceberem as disputas entre grupos para se apropriarem do espaço, associavam a sua não participação nesses conflitos ao facto de permaneceram durante mais tempo sob a alçada da escola.

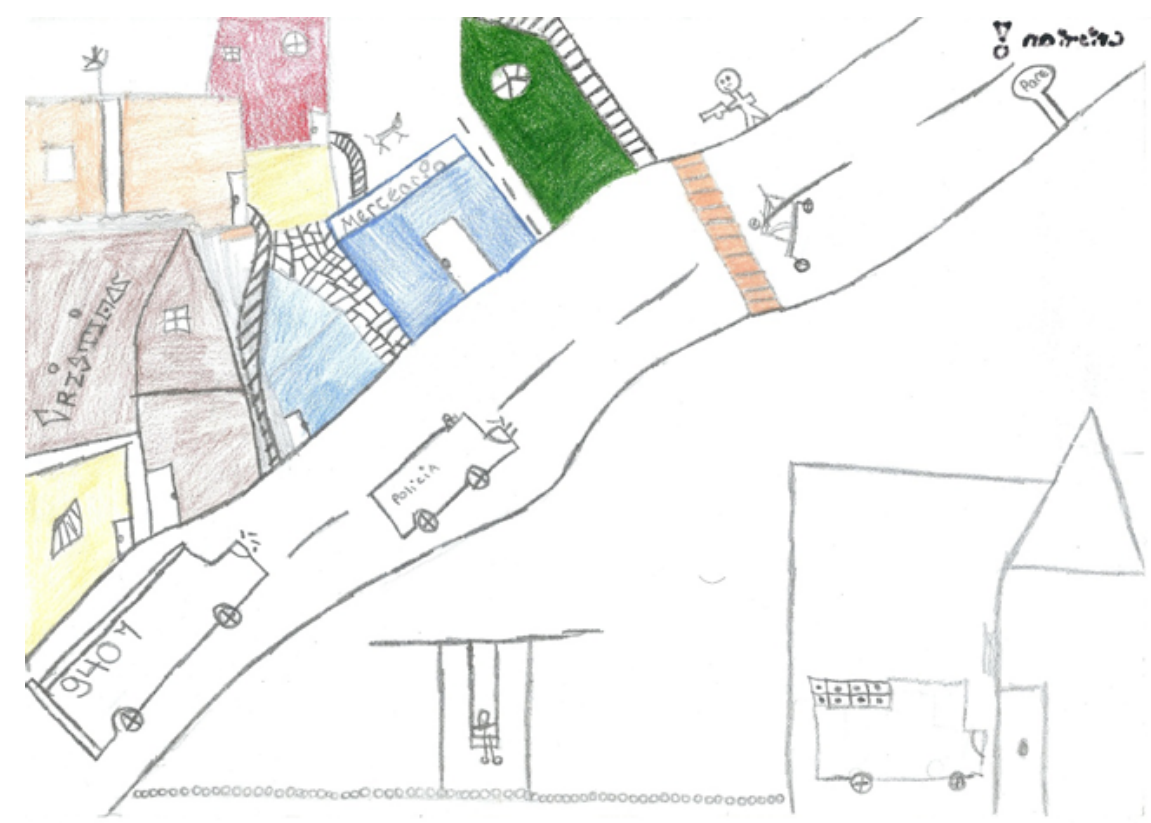

Figura 2. Mapa mental/O território e suas relações de poder. Autor: Estudante/PEI. 
No mapa mental apresentado, visualizamos no mesmo território a associação entre os espaços de lazer e das brincadeiras e as disputas no território, o que podemos perceber através da representação de uma pessoa apontando uma arma de fogo e de um carro de polícia a circular pelo bairro.

Nesse sentido, o território é uma construção histórica e de forte cunho «social formado a partir das relações de poder (concretas ou simbólicas) que envolvem concomitantemente, sociedade e espaço geográfico» (Haesbaert, 2007, pág. 42). Assim, no nosso contexto, a escola, ao procurar a apropriação dos espaços do bairro, entra nessas disputas pelo espaço como vetor de territorialização, a fim de deter o poder sobre esses espaços em determinados momentos. Desta forma, ao lutar e criar estratégias pela apropriação do espaço são criadas novas territorialidades, influenciando consequentemente novas relações sobre o espaço.

Desse modo, ao visar a utilização de espaços fora dos muros escolares para o desenvolvimento das oficinas e a consequente apropriação desses espaços, a escola necessita de criar estratégias para exercer o seu poder sobre aquele espaço. A este respeito, podemos visualizar aqui o caso de uma praça nas imediações da escola que, tal como já referimos, é usada como espaço educativo na Escola Municipal Admirável. A professora comunitária, ao propor a utilização do espaço, enfrentou as relações ali existentes ligadas ao tráfico de droga e episódios de violência, o que levou a criar, através da escola, novas territorialidades naquele espaço em determinados momentos.

Utilizamos a praça para a oficina de fanfarra e skate, só que a praça fica perto do posto e fazemos muito barulho. E aí veio uma senhora reclamar connosco porque estávamos a ocupar a praça e a fazer barulho... E aí começámos a falar com ela com calma, explicando que ali também era um espaço utilizado por consumidores de droga, etc. e inclusive um professor que também lá estava perguntou: «quando andam por aqui consumidores de droga, a senhora também reclama com eles?» Claro que não, respondeu ela, e então, foi isso que questionámos, então o consumidor de droga pode usar a praça e a senhora não reclama e nós não podemos?. E foi isso que explicámos, que estávamos a tentar ocupar a praça de uma outra forma e estamos até hoje lá. E apesar de não ser sempre, para podermos utilizar a praça tinha que haver polícia presente para podermos ficar ali com as crianças, porque de vez em quando havia gente a usar droga ali e hoje é um espaço tranquilo, aliás acho que hoje o espaço é nosso, pelo menos 
quando estamos lá. E hoje, mesmo sem a presença da polícia, nós estamos lá. E claro que às vezes surgem situações de consumo de droga, mas mesmo assim já estamos lá e ocupamos o espaço. O mal é que as crianças estão ali e veem o que se passa, mas estamos a atribuir um novo significando a esse espaço. (Flor)

Como podemos perceber, para que a escola pudesse utilizar a praça, a professora comunitária teve um diálogo paulatino com as pessoas da comunidade, sensibilizando-as para a possibilidade de ocupação do espaço pelas crianças e adolescentes da escola. Isso fez com que novas relações fossem criadas na praça, pelo menos quando as crianças ali estão. Outra estratégia utilizada foi o auxílio da polícia, o que marca a disputa e as relações de poder naquele espaço. É importante observar também que, como uma das estratégias, a escola, a partir das oficinas, pintou a praça, modificando esteticamente o espaço e marcando a presença e o domínio da escola na praça. Podemos entender essa ação como uma estratégia de valorização de espaços desenvolvida através das oficinas do PEI, pois visou a melhoria do espaço da praça para as práticas do PEI, colocando a escola e os seus sujeitos como principais atores territorializantes do referido espaço. Além disso, normalmente, a escola divulga essas melhorias realizadas no bairro, no âmbito do PEI, nos jornais do programa, que é desenvolvido na escola e têm circulação local.

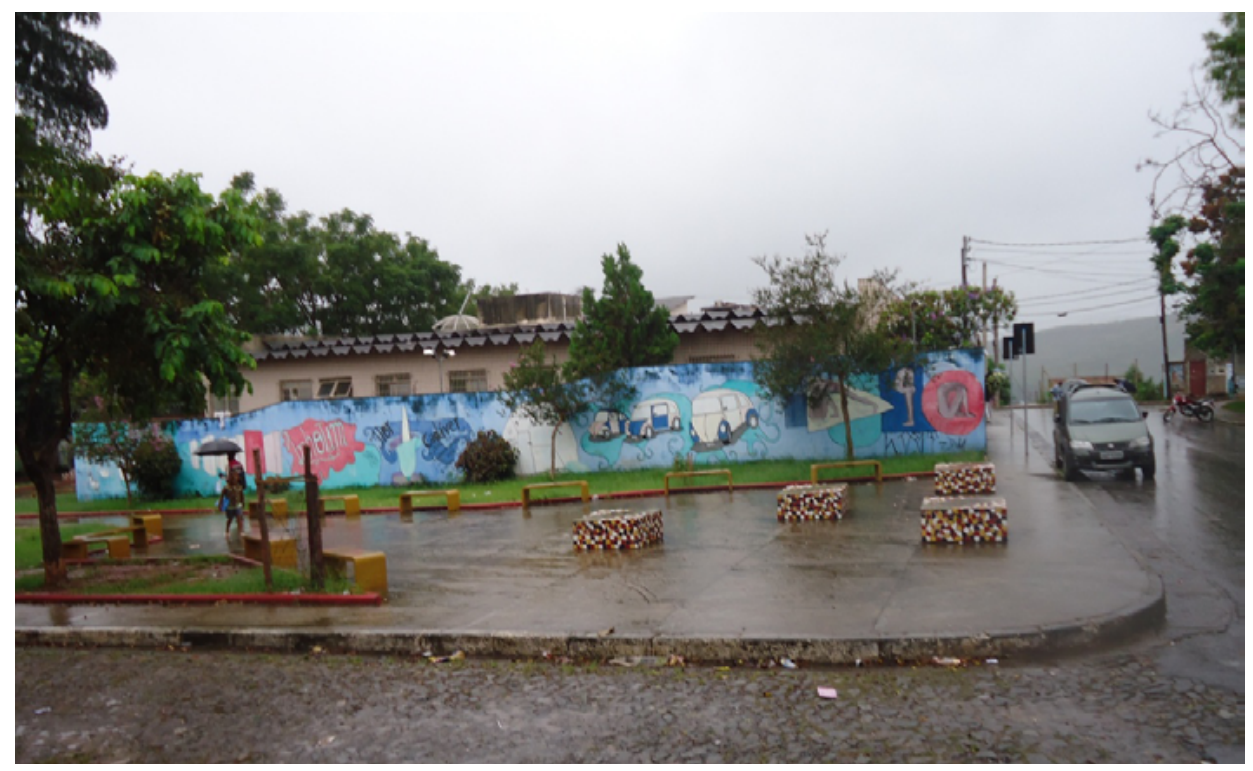

Figura 3. Praça Padre Marcelo no ambiente da Escola Municipal Admirável. Fonte: autores/Arquivos de campo. 
Ressalta-se que o facto de a escola criar essas estratégias para lidar com os conflitos inerentes ao espaço e ao mesmo tempo reabilitar determinados espaços do bairro, a fim de que os estudantes possam apropriá-lo, não significa a anulação dos conflitos e das relações de poder existentes ali, nem das outras relações que fazem parte daquele território. Como assinalámos, um mesmo espaço pode ser apropriado de maneiras distintas e por diferentes sujeitos. Voltando ao caso da praça, vejamos o discurso de um estudante.

Henrique: No dia do meu aniversário houve um tiroteio aqui na pracinha. Os miúdos estavam a atirar-me fubá e eu fui tomar banho. A minha irmã estava a brincar na pracinha, aí chega um homem e começou logo a atirar, a atirar para todo o lado. A minha irmã estava lá na pracinha e fugiu para a casa do meu primo e ficou lá. Eu saí da casa de banho a correr preocupado com os meus irmãos. Nem dei conta, saí com a toalha e tudo lá para fora.

Investigador: Estavas em casa e ouviste os tiros?

Henrique: Na casa de banho, eu estava a tomar banho, a tirar o fubá da cara. (risos)

Investigador: Isso já foi há muito tempo?

Henrique: Foi o ano passado, no dia do meu aniversário.

Investigador: Ninguém ficou ferido?

Henrique: Sim, um homem, ficou a coxear. Eu não vi bem porque foi a para a 'lan house'. Mas ele saiu a coxear.

Investigador: Mas é difícil situações dessas acontecerem?

Henrique: É difícil, desde que estou aqui, é a primeira vez que acontece. $\mathrm{Na}$ pracinha, a brincar é a primeira vez que aconteceu isso.

\section{(Arquivos de Campo)}

Como podemos observar, a mesma praça utilizada pela escola nos dias de semanas, nos fins de semana apresenta outras territorialidades, o que supõe que o território educativo, ao relacionar-se com as dimensões do poder, é marcado também por processos de desterritorialização e reterritorialização. 
No que diz respeito a esses processos, podemos entendê-los como a mudança de relações que se estabelece num espaço.

A desterritorialização vem sempre acompanhada da reterritorialização. Nesse sentido, de acordo com Haesbaert (2004), a territorialização é, portanto, um recurso básico para o desenvolvimento da humanidade. Nesse contexto, as formas de territorialização são dinâmicas e relacionais, assim, a maneira como essas relações se evidenciam, em determinados momentos, é que vai definir o território, as fronteiras e as regiões, uma vez que eles dependem «do movimento, fluidez, interconexão - em síntese e num sentido mais amplo, temporalidade» (Haesbaert, 2004, p.82).

Ao transportarmos essa ideia para a dinâmica do PEI no Alto Vera Cruz e ao pretendermos delinear um entendimento conceitual da expressão território educativo, as disputas e conflitos pelo espaço aparecem, portanto, como fortes elementos. Podemos assim dizer, que se centraliza uma conceção de que o território, juntamente com as outras relações aqui expostas, é também apropriado por relações de poder.

Então, as estratégias de territorialização aplicadas pela escola, no contexto investigado, podem desencadear um espaço transformado que se particulariza, na medida em que, ao dominá-lo, constituem-se territorialidades do e no espaço apropriado. Isto é, criam-se territorialidades no território ocupado e este passa a ser entendido juntamente com as relações de poder dos grupos que o apropriam. Essas territorialidades ligam-se também aos processos de atribuição de um novo significado e de uma nova identificação aos espaços, o que pode gerar diversas identidades territoriais. A esse respeito:

Todas as ressignificações ou, no nosso caso, reidentificações, estão mergulhadas em relações de poder e, deste modo, sujeitas aos mais diversos jogos, ora mais impositivos, ora mais abertos, que este poder implica dentro de uma sociedade profundamente desigual e marcada por múltiplos processos de dominação. Se identificar(- se) é também, de alguma forma, classificar, estas classificações com que ressignificamos o mundo, nós e os outros, inclusive através dos territórios, são objetos de intensas disputas entre aqueles que têm o poder de formular e mesmo fixar estas classificações. (Haesbaert, 2007, p. 37) 
Assim, podemos dizer que a territorialização dos espaços do bairro pela escola ocorre de forma aliada a outras relações de grupos, que também imprimem determinadas identidades no espaço como, por exemplo, grupos de jovens que frequentam a praça nos fins de semana, a polícia que muitas vezes marca presença naquele lugar, bem como a presença de consumidores de droga que, por vezes, ainda utilizam a praça, entrando na disputa pela territorialização do espaço. Com isso, concebe-se o território educativo também a partir do confronto de grupos que desejam imprimir as suas identidades no espaço. A escola, nesse sentido, entra na disputa pela apropriação do espaço a partir da ocupação do movimento de inserção dos estudantes e educadores nesses espaços em momentos de circulação promovidos pelo Programa Escola Integrada.

\section{Considerações finais}

Como vimos, os processos de constituição dos territórios educativos são intensos e complexos. A partir da dinâmica desenvolvida pelo PEI no bairro e na cidade e pelas relações que daí derivam, percebe-se a constituição de um território educativo composto de multiterritorialidades que, em diálogo, afirmam a identidade da comunidade e do território do ambiente escolar, ampliando as relações da escola e constituindo redes. Esses elementos valorizam e intensificam, mesmo face às relações de poder, a identidade territorial e o sentido de bairro (vizinhança). Assim, o território educativo, ao assumir contornos fluidos e múltiplos, incorpora um caráter multiterritorial. Nesse sentido, como afirma (Haesbaert, 2007):

O território, como espaço dominado e/ou apropriado, manifesta hoje um sentido multiescalar e multidimensional que só pode ser devidamente apreendido dentro de uma conceção de multiplicidade, de uma multiterritorialidade. Toda ação que se pretenda efetivamente transformadora, hoje, necessita, obrigatoriamente, encarar esta questão: ou se trabalha com a multiplicidade de nossos territórios, ou não se alcançará a transformação que almejamos. (p. 42-4) 
O território educativo também potencializa o sentimento de pertença e topofilia ao/pelo bairro, uma vez que uma das aceções da categoria espacial bairro está intimamente ligada à afirmação das identidades e à coesão social.

Ao pensarmos o território educativo a partir do Programa Escola Integrada, percebemos que ele suscita a produção de um espaço geográfico educativo marcado por fluidez e maleabilidade. Espaço esse que, ao ser apropriado pela escola, ajuda a identificação dos estudantes com seu espaço de vivência, impulsiona ações coletivas em prol da melhoria do bairro e das condições de vida de seus moradores. A Educação Integral confere e evoca, portanto, um novo sentido à escola tentando superar a ideia de espaço/território escolar $\mathrm{e}$ afirmar a ideia de território educativo, múltiplo e plural.

\section{Referências}

Amorim Filho, O. B. (1999). «Topofilia, Topofobia e Topocídio em Minas Gerais». In: Del Rio, V; Oliveira, L. (1999). Percepção Ambiental: a perspectiva brasileira. (pp. 139-152). São Carlos: UFSCar/ Studio Nobel.

Arroyo, M. G. (2000) Oficio de Mestre: imagens e auto-imagens. Petrópolis: Vozes.

- (2012) «O direito a tempos-espaços de um justo e digno viver». In: Moll, JAQUELINE. Caminhos da Educação Integral no Brasil: direito a outros tempos espaços educativos. Porto Alegre: Penso Editora.

Brasil, Ministério da Educação (2008). Caderno Educação Integral. 1. ${ }^{a}$ edição. Brasília. Recuperado em 01 out 2015. http://portal.mec. gov.br/dmdocuments/cadfinal_educ integral.pdf

- (2009). Educação integral: texto referência para o debate nacional. 1. a edição. Brasília. Recuperado em 15 nov 2015. http://portal.mec. gov.br/dmdocuments/cadfinal_educ_integral.pdf

Carlos, A. F. A. (1996) O lugar no/do mundo. São Paulo: Hucitec.

CenPeC (2011). Tendências para educação integral. $1^{\circ}$ Edição. São Paulo. Recuperado 01 out 2015. http://ww2.itau.com.br/itausocial2/pdf/ ed_integral.pdf

Geertz, C. (1989). A interpretação das culturas. Rio de janeiro: Guanabara Koogan. 
GuARÁ, I. M. F. R. (2009). «Educação e desenvolvimento integral: articulando saberes na escola e além da escola». In: Em Aberto. Instituto Nacional de Estudos e Pesquisa Educacionais Anísio Teixeira. Brasília, (v. 22, n. 80), 65-81.

Haesbaert, R. (2004). O mito da desterritorialização: do «fim dos territórios»» à multiteritorialidade. Rio de Janeiro: Bertrand Brasil.

- (2007). Território e Multiterritorialidade: um debate. In: Revista GEOgraphia. (Ano IX, n. 17). Recuperado em 22 jun. 2014. http://www. uff.br/geographia/ojs/index.php/geographia/article/viewFi$\underline{\text { le/213/205 }}$

Kozel, S. \& Lima, A. M. L. (s/f). «Lugar e Mapa mental: uma análise possível». In: Geografia. Londrina, (v. 18, n. 1), 207-231.

Kozel, S. (2010) Representação do espaço sob a ótica, dos conceitos: mundo vivido e dialogismo. 1. ' edição. Porto Alegre. Recuperado em: 18 out. 2015. file:///C:/Users/m12991840/Downloads/T0039\%20 -\%20Salete\%20KOZEL\%20(1).pdf

Magnani, J.G.C. (2002). «De perto e de Dentro: notas para uma etnografia urbana». In. Revista Brasileira de Ciências Sociais. São Paulo, (vol. 17, n.49), 11-29.

SAntos, M. (2000). «Território e sociedade: entrevista com Milton Santos». São Paulo: Fundação Perseu Abramo.

Souza, E. A. S. Pedon, N. R. (2007). «Território e Identidade». In. Revista da Associação dos Geógrafos Brasileiros. Mato Grosso do Sul. (Vol.1, n. 6), p. 126-148.

Tuan, YI-Fu. (1980). Topofilia um estudo da percepção, atitudes e valores do meio ambiente. São Paulo. Difel. 